\title{
Experimental and numerical analysis of fillet-welded joints under low-cycle fatigue loading by means of full-field techniques
}

\author{
Pasqualino Corigliano', Vincenzo Crupi', Wolfgang Fricke ${ }^{2}$, \\ Nils Friedrich ${ }^{2}$ and Eugenio Guglielmino'
}

\begin{abstract}
The welded structures used in the naval field are generally subjected to fluctuating stress over time. In some structural welded details, due to changing loading conditions, significant elastic-plastic deformation can arise, which may lead to the failure of the structure after a relatively low number of cycles. The aim of this scientific work was to investigate the behavior of welded T-joints under low-cycle fatigue using full-field techniques: digital image correlation and infrared thermography. Low-cycle fatigue tests were carried out on welded "small-scale" specimens with the aim of obtaining loading and boundary conditions similar to those that occur in "large-scale" components in their real operating conditions. A nonlinear finite element analysis was also performed. The material curves, relative to different zones (base material, heat-affected zone, weld), were obtained by hardness measurements, which were done by means of a fully automated hardness scanner with high resolution. This innovative technique, based on the ultrasonic contact impedance method, allowed to identify the different zones (base material, heat-affected zone, weld metal) and to assess their cyclic curves, which were considered in the finite element model. Finally, the finite element model was validated experimentally comparing the results with the measurements obtained using the digital image correlation technique. The applied procedure allows providing useful information to the development of models for the prediction of fracture and fatigue behavior of the welded joints under the low-cycle fatigue loading.
\end{abstract}

\section{Keywords}

Low-cycle fatigue test, welded ship structure, digital image correlation, thermographic analysis, finite element analysis

Date received: I July 2014; accepted: 8 January 2015

\section{Introduction}

Fatigue failure of ship structures is an extremely localized process, depending on parameters such as local geometry, loading conditions, and material properties. These effects become even more important and complicated to understand when welded joints are assessed. The welding process induces variations depending also on microstructural factors. The local mechanical properties are expected to change from the weld metal (WM) to the heat-affected zone (HAZ) and generally they will be different from the base material (BM) ones. ${ }^{1}$ Local approaches are applied in these cases and are mainly based on local displacement and strain measurements by strain gages. Several approaches for fatigue strength assessment of welded joints have been developed. ${ }^{2,3}$ The most common approaches include: nominal stress approach (the simplest and most frequently used), structural hot-spot stress approach, ${ }^{4,5}$ effective notch stress approach using the fictitious notch radius, 3,6 notch stress intensity factor approach, ${ }^{7,8}$ critical distance methods, ${ }^{9,10}$ thermographic method, ${ }^{10-12}$ notch strain approach, ${ }^{13}$ and crack propagation approach. ${ }^{14}$ The assessment becomes more complex in the presence of a multiaxial stress state. ${ }^{15-17}$

Some fatigue cracks have been detected in ship structures within a few years of their service life, and this type of fatigue cannot be adequately explained by the high-cycle fatigue (HCF) approaches

\footnotetext{
'Department of Electronic Engineering, Chemistry and Industrial Engineering, University of Messina, Messina, Italy

${ }^{2}$ Hamburg University of Technology, Institut für Konstruktion und Festigkeit von Schiffen, Germany

\section{Corresponding author:}

Pasqualino Corigliano, Department of Electronic Engineering, Chemistry and Industrial Engineering, University of Messina, Contrada di Dio - Sant'Agata, Messina 98I66, Italy.

Email: pcorigliano@unime.it
} 
based on the S-N curve. Most ship structures consist of plate details, connected to longitudinal and transverse members by welded joints, which are the sites of high stress concentrations, and are subject to severe environmental loading from wave pressure, ship motions and loading/unloading operations, which induce significant fatigue loads. The presence of stress concentrations and fatigue loads leads to cyclic stress that exceeds the yield stress locally and some cracks, related to low-cycle fatigue (LCF), can be detected in ship structures.

The aim of this scientific work was to set up fullfield techniques (digital image correlation (DIC) and infrared thermography) in order to evaluate how local aspects affect the LCF life of T-welded joint. The surface temperature of the specimens during all the fatigue tests was detected by means of an infrared thermography (IRT), which gave interesting information about the evolution of the temperature at the crack tip during the fatigue life. A specific procedure was developed to analyze the response of the investigated welded joint under LCF loading. It is based on the following steps: the hardness measurements, using an innovative method for the identification of the different zones (BM, HAZ, WM) and the assessment of their cyclic curves, the realization of a nonlinear finite element (FE) analysis considering the different material properties, the validation of FE model by means of the experimental data, obtained by DIC technique.

\section{Materials and methods}

\section{Test specimen and test conditions}

The basis of the tests are the experimental analyses of the large-scale model (Figure 1), taken from ship welded structures which were carried out at TUHH

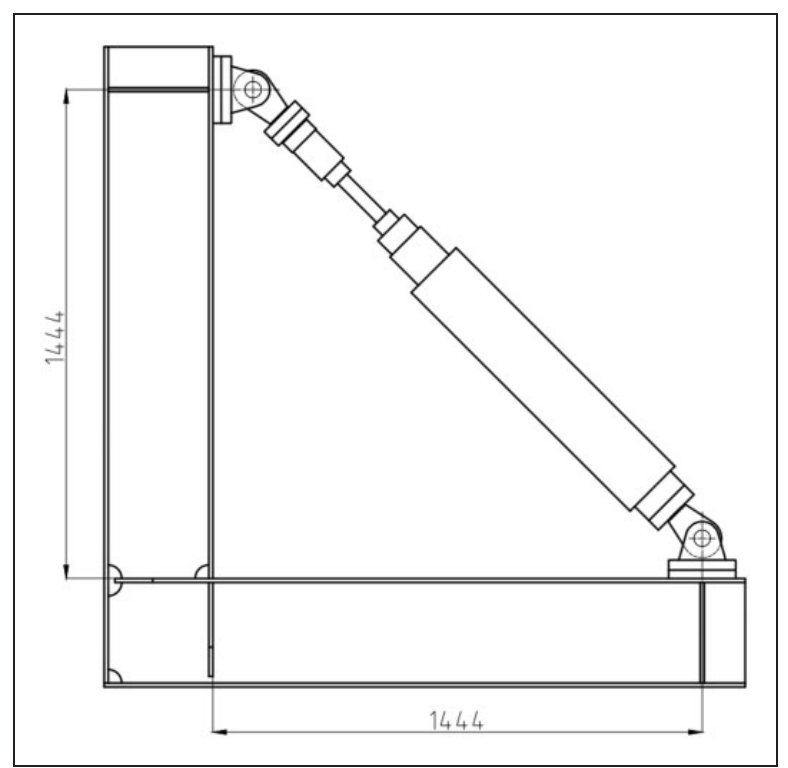

Figure I. Large-scale model.
(Hamburg University of Technology) and the results are reported in Crupi et al. ${ }^{18}$

The small-scale specimens (Figure 2) arise from the need to reproduce boundary and loading conditions similar to those of the large-scale model. The smallscale specimens were realized welding a plate (the lower plate, shown in Figure 2) to the continuous plate (the upper plate shown in Figure 2), which has a "tail", as shown in the detail "A" of Figure 3. Dimensions of the small-scale specimens are reported

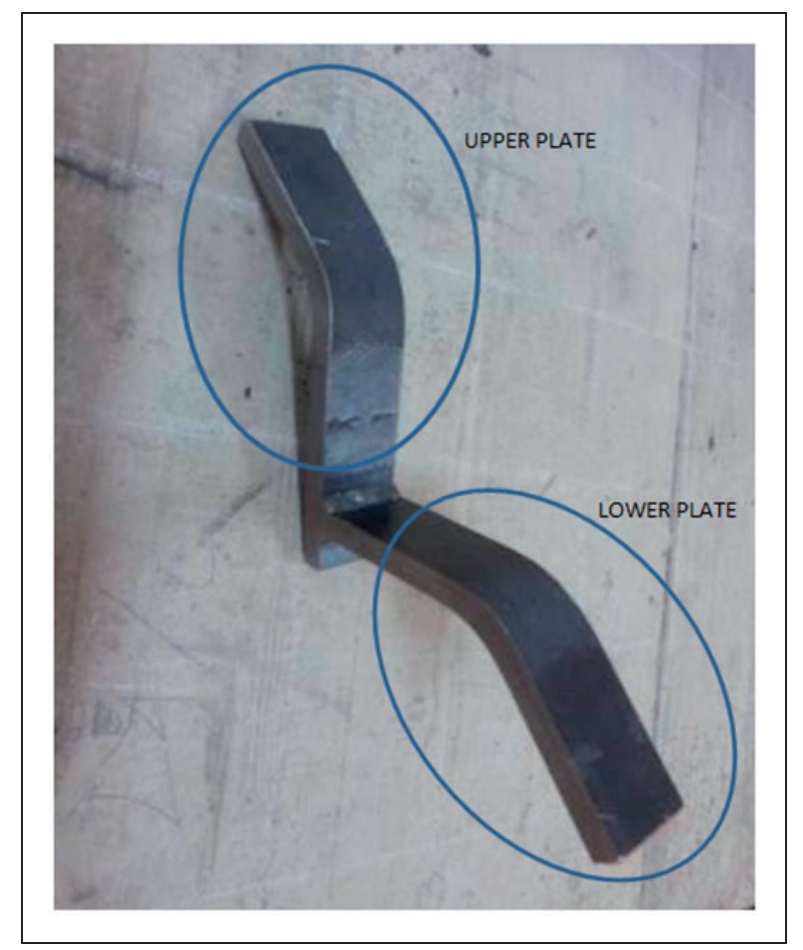

Figure 2. Small-scale specimen.

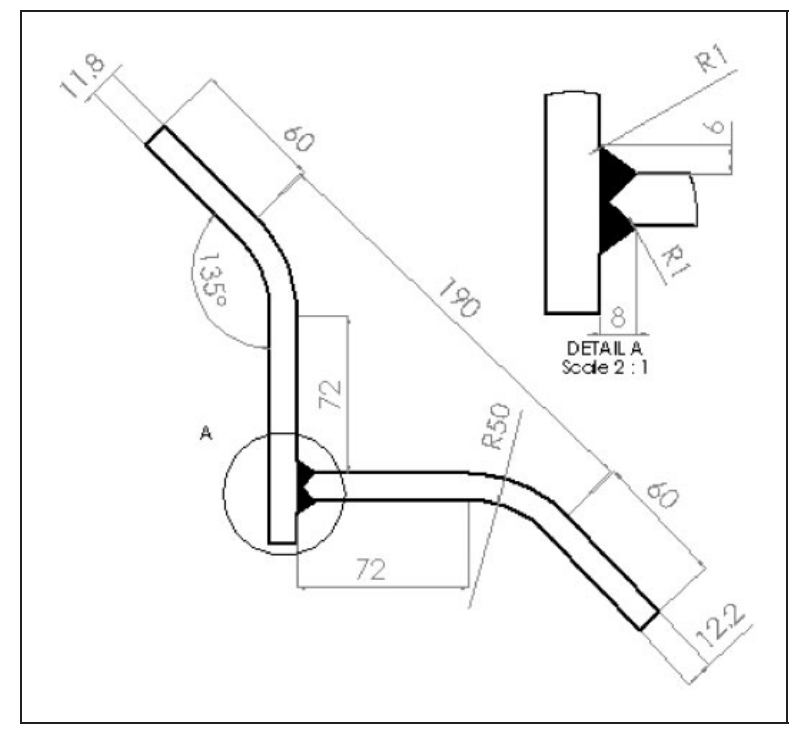

Figure 3. Geometry and nominal dimensions of small-scale specimen. 
in Figure 3. The width of the two plates is $40 \mathrm{~mm}$ and the thickness was found to deviate from the nominal value of $12 \mathrm{~mm}$, i.e. $11.8 \mathrm{~mm}$ for the upper plate and $12.2 \mathrm{~mm}$ for the lower plate.

The local geometry of the weld is not exactly the same for the investigated specimens. Figure 4 shows a comparison between the section of the real fillet weld of a specimen and the nominal profile considered in the finite element analysis (FEA). Mild steel S235JR was used for the material, being widely applied in shipbuilding. Welding was performed using the MAG process with $1.2 \mathrm{~mm}$ thick wire acc. to DIN ISO 14341-A-G4Si1.

Displacement-controlled fatigue tests with displacement ratio $R_{u}=-1$ were carried out using an MTS 810 machine with a load cell of $250 \mathrm{kN}$. The images of the specimens during the tests were acquired and processed by means of the ARAMIS system using the DIC technique. The infrared cameras, used for the thermographic investigations, are the FLIR SC 7200 and A40 model. The infrared images, which have a resolution of $320 \times 240$ pixels, were analyzed by the software Altair.

Before the fatigue tests, two tensile tests with dogbone specimens made from the same steel were carried out under load control at a velocity of $5 \mathrm{MPa} / \mathrm{s}$. The results of the tests, in terms of Young's modulus $(E)$, yield strength $\left(\sigma_{y}\right)$, ultimate strength $\left(\sigma_{u}\right)$, and ultimate strain $\left(\varepsilon_{u}\right)$, are reported in Table 1 .

\section{Hardness measurements}

Hardness measurements, with a fully automated hardness scanner with high resolution, using the ultrasonic contact impedance (UCI) method, were performed at the Helmholtz Zentrum in Geesthacht, Germany. The UCI method is based on the natural resonance frequency of a bar, which pushes the Vickers diamond

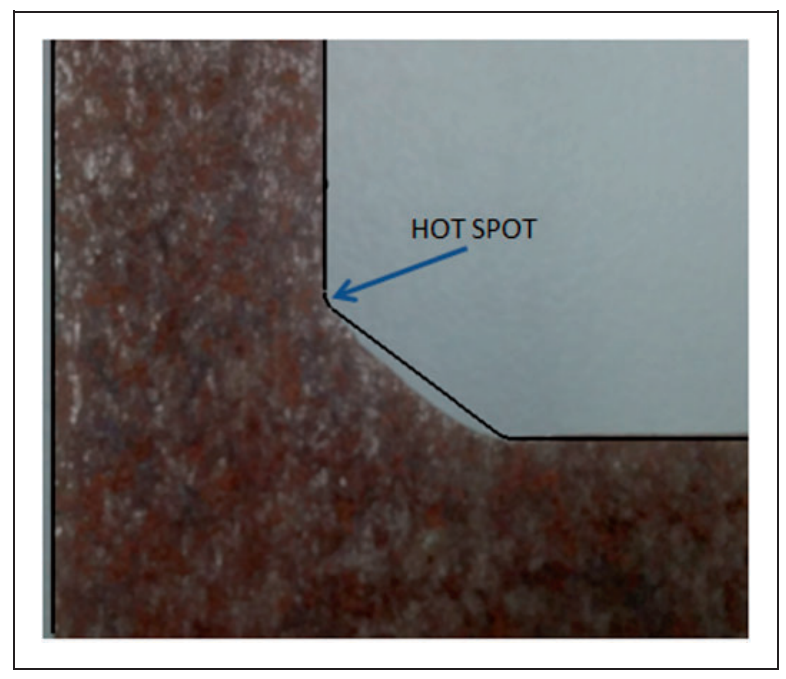

Figure 4. Section of the real fillet weld of a specimen and nominal profile considered in the finite element analysis. to penetrate into the sample. The measured frequency change depends on the size of the contact surface between the diamond and the sample and thus, for a fixed test load, on the hardness of the sample. The aim was to investigate how hardness values influence the global material behavior. Different groups of hardness measurements on the surface, which is a section obtained from cutting the specimen at the middle of the width $(20 \mathrm{~mm})$, were identified and they are shown in Figure 5. No increased hardness was found in the HAZ with respect to WM.

The relationship between tensile strength $\sigma_{u}$ (in $\mathrm{MPa}$ ) and Brinell hardness (HB) can be described by a second-order polynomial equation, ${ }^{19}$ given by

$$
\sigma_{u}=0.0012 \cdot(H B)^{2}+3.3 \cdot(H B)
$$

This equation is a better approximation, especially for high hardness values, than the commonly used linear relations. The yield strength $\left(\sigma_{y}\right)$ was also evaluated in order to correlate it with HB hardness, according to equation (2). ${ }^{19} \mathrm{HV}$ values were first converted in HB hardness according to the EN ISO 18265 standard, then static tensile properties were calculated.

$$
\sigma_{y}=0.0039 \cdot(H B)^{2}+1.62 \cdot(H B)
$$

\section{Tests and analyses performed Low-cycle fatigue tests}

Fatigue tests were carried out with small-scale specimens under displacement $\Delta u$ control (a sinusoidal waveform was used for all tests) in LCF regime and the test parameters are reported in Table 2. The acquisition of the images for the DIC analysis suggested a low value of the frequency during the LCF tests in order to have more data to evaluate hysteresis loops, while the thermographic analysis (IRT) suggests a higher frequency of the LCF tests in order to be less influenced by the environment. For this reason, the test frequencies were $0.1 \mathrm{~Hz}$ and $1 \mathrm{~Hz}$, respectively. The crack originates at the upper plate in the weld toe notch and propagates into the same plate along the transverse direction of the plate, as shown in Figure 6.

The values of the maximum and minimum load versus the number of cycles are shown in Figure 7 for the test 1 , carried out at displacement amplitude $u_{a}= \pm 2 \mathrm{~mm}$ and displacement ratio $R_{u}=-1$. At the beginning of the test, the measured force range is almost constant, then, after few cycles, it starts

Table I. Mechanical properties of the specimens made with the same steel used for the base material.

\begin{tabular}{lllll}
\hline & $E(\mathrm{GPa})$ & $\sigma_{y}(\mathrm{MPa})$ & $\sigma_{u}(\mathrm{MPa})$ & $\varepsilon_{u}(\%)$ \\
\hline Test I & 205 & 345 & 475 & 21.8 \\
Test 2 & 225 & 320 & 477 & 22.1 \\
\hline
\end{tabular}




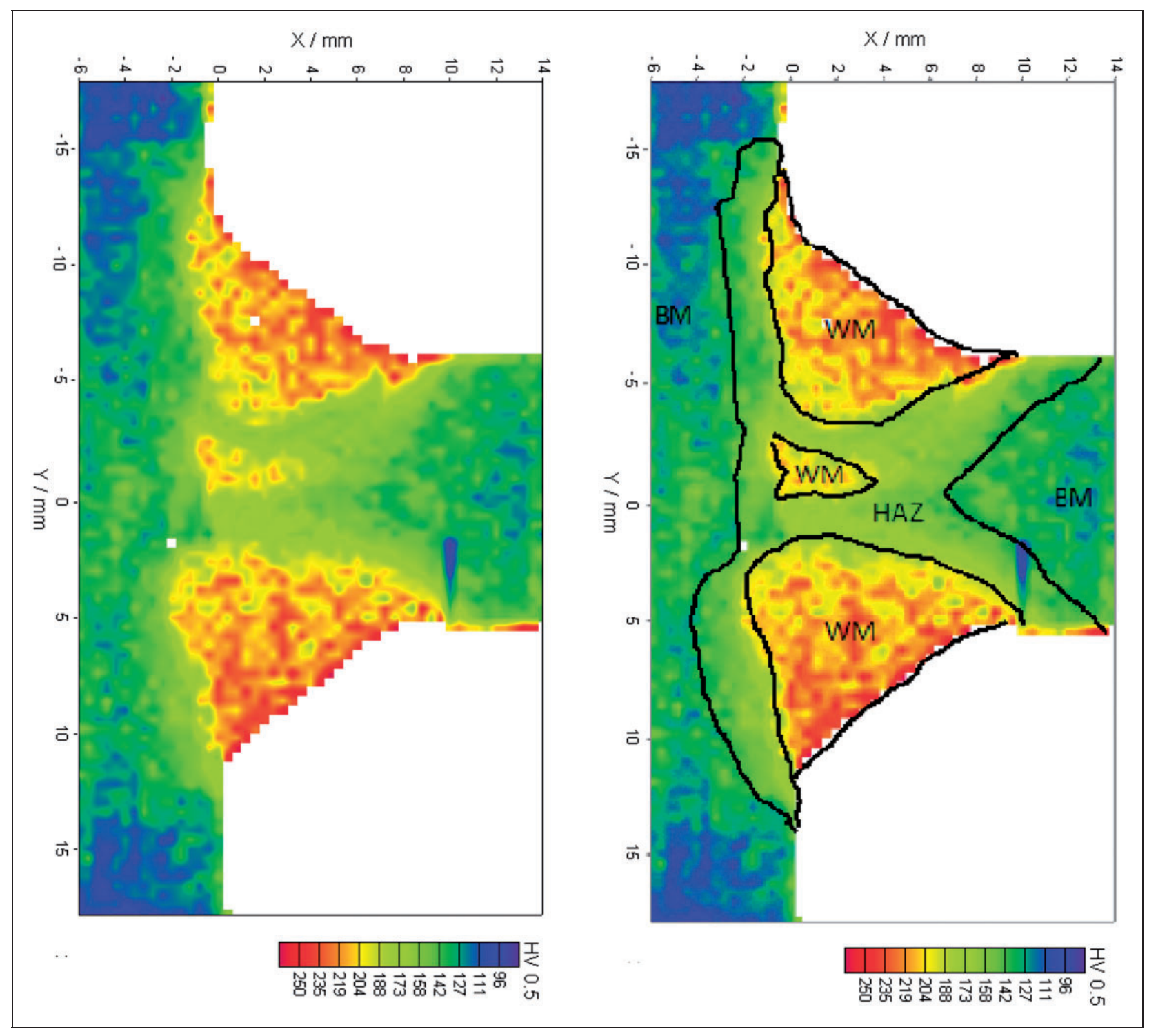

Figure 5. Hardness measurement results and identification of the three zones (WM, HAZ, BM). WM: weld metal; HAZ: heat-affected zone; BM: base material.

to decrease. This phenomenon is confirmed by the hysteresis cycles. Figure 8 shows the most representative hysteresis cycles, relative to the same test. The hysteresis loop is constant at the initial period (up to 200 cycles) and it reduces as soon as the crack starts growing. The values of the nominal stress amplitude $\sigma_{a}$ were evaluated for all tests on the upper plate, at the toe of the fillet weld, i.e. the hot spot stress, using the beam theory. The load values measured by the load cell after a 100 cycles were used for this calculation. Figure 9(a) and (b) shows the $\Delta u$ versus $N_{f}$ and $\sigma_{a}$ versus $N_{f}$ curves for all tests in a bi-logarithmic scale, with their linear regression curves, where $N_{f}$ is the number of cycles to specimen fracture.

\section{Thermographic method}

An infrared camera was used during the fatigue tests in order to detect the point of crack initiation.
The evolution of the increment of the maximum temperature with respect to the initial temperature $\Delta T$, as a function of the number of loading cycles $(N)$, is analyzed in Figure 10. The figure clearly shows that the obtained $\Delta T-N$ curve is characterized by three subsequent phases (namely, Phases I, II, and III). This pattern was detected in $\mathrm{HCF}^{10}$ and $\mathrm{LCF}^{20}$ behavior of common engineering metals and welded joints and also for NiTi shape memory alloys under fatigue loading. ${ }^{21}$

The thermal increments during the LCF life were correlated to the hysteresis loops derived from the traditional procedure in Crupi et al., ${ }^{20}$ confirming that there is a correlation between the stable hysteresis loops and the stabilized temperature. In particular, when a specimen is cyclically loaded above its fatigue limit, the temperature of the specimen surface usually rises quickly in the initial phase (Phase I), then a low and constant slope in the $\Delta T-N$ curve follows 
Table 2. Test parameters.

\begin{tabular}{lllllll}
\hline Test & $\begin{array}{l}\text { Displacement } \\
\text { amplitude, } u_{a}(\mathrm{~mm})\end{array}$ & $\begin{array}{l}\text { Displacement } \\
\text { ratio, } R_{u}\end{array}$ & $\begin{array}{l}\text { Test frequency, } \\
f(\mathrm{~Hz})\end{array}$ & $\begin{array}{l}\text { IRT aquisition } \\
\text { frequency }\end{array}$ & $\begin{array}{l}\text { DIC aquisition } \\
\text { frequency }\end{array}$ & $\begin{array}{l}\text { Cycles to } \\
\text { failure, } N_{f}\end{array}$ \\
\hline $\mathrm{I}$ & 2 & $-\mathrm{I}$ & $\mathrm{I}$ & $\mathrm{No}$ & $6 \mathrm{~Hz}$ & 620 \\
2 & $\mathrm{I}$ & $-\mathrm{I}$ & $\mathrm{I}$ & $2 \mathrm{~Hz}$ & $6 \mathrm{~Hz}$ & 5000 \\
3 & $\mathrm{I} .5$ & $-\mathrm{I}$ & $\mathrm{I}$ & $2 \mathrm{~Hz}$ & $6 \mathrm{~Hz}$ & 1028 \\
4 & 2 & $-\mathrm{I}$ & $\mathrm{I}$ & $2 \mathrm{~Hz}$ & $6 \mathrm{~Hz}$ & 628 \\
5 & 2 & $-\mathrm{I}$ & 0.1 & $\mathrm{No}$ & $6 \mathrm{~Hz}$ & 510 (interrupted) \\
6 & 1.5 & $-\mathrm{I}$ & $\mathrm{I}$ & $2 \mathrm{~Hz}$ & $6 \mathrm{~Hz}$ & $23 \mathrm{I} 2$ \\
7 & $\mathrm{I}$ & $-\mathrm{I}$ & $\mathrm{I}$ & $2 \mathrm{~Hz}$ & $6 \mathrm{~Hz}$ & 8400 \\
8 & 2.5 & $-\mathrm{I}$ & 0.1 & $\mathrm{IHz}$ & $6 \mathrm{~Hz}$ & 375 \\
9 & 2.5 & $-\mathrm{I}$ & 0.1 & $\mathrm{No}$ & $2 \mathrm{~Hz}$ & 430 \\
\hline
\end{tabular}

IRT: infrared thermography; DIC: digital image correlation

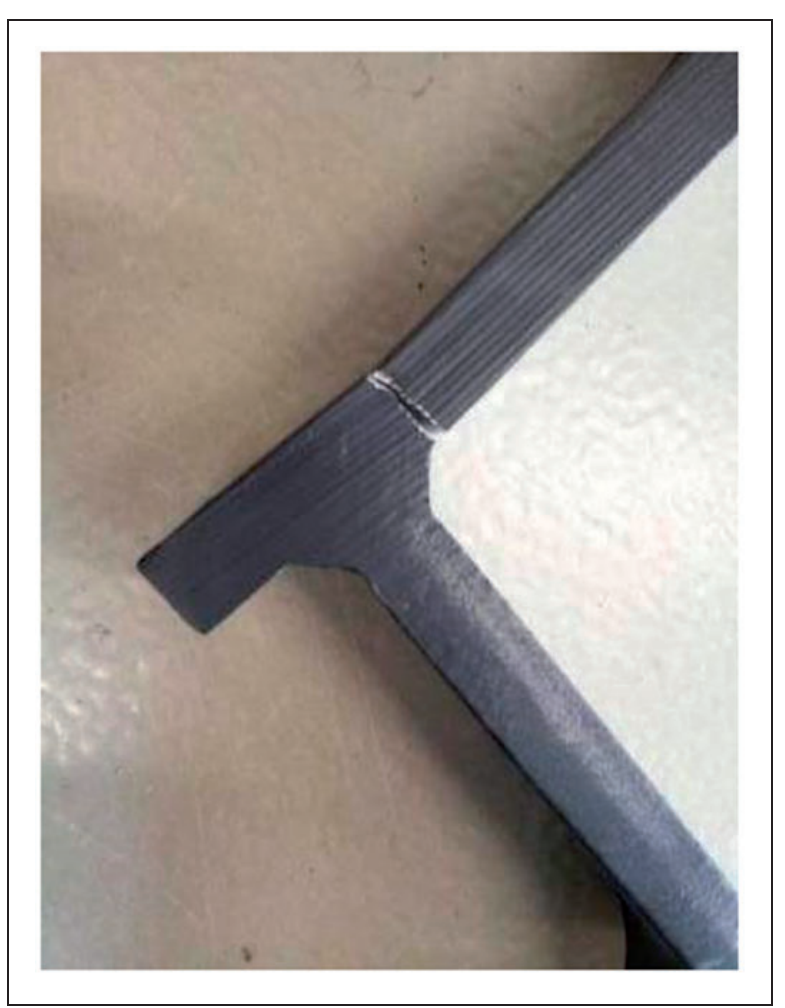

Figure 6. Typical fatigue crack.

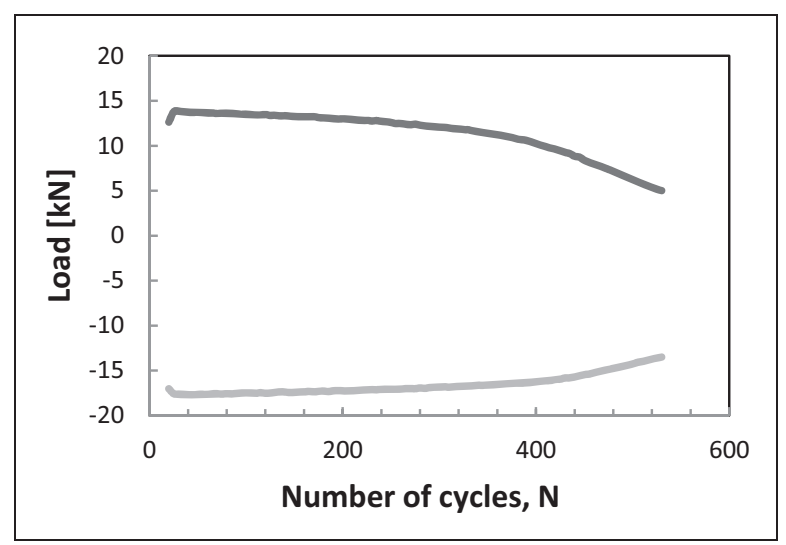

Figure 7. Max. and min. load vs. time (test no. I).

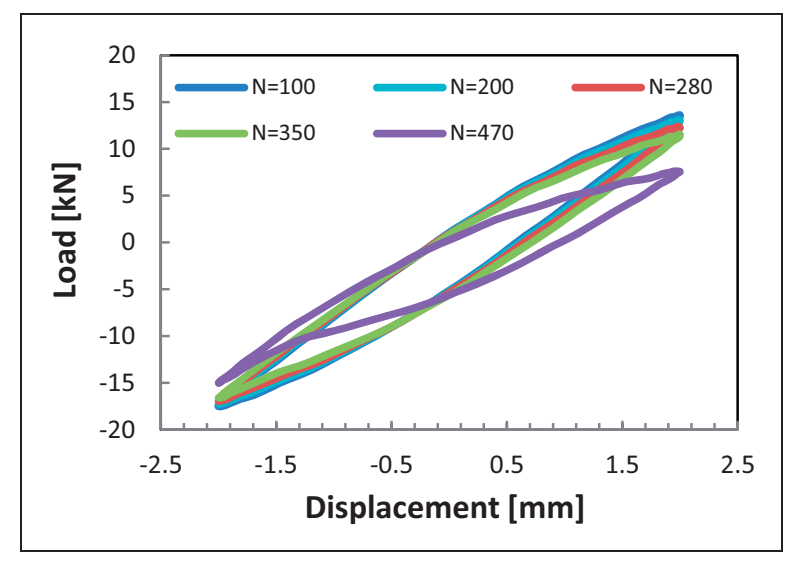

Figure 8. Hysteresis loops, load vs. $\Delta u$ (test no. I).

(Phase II), and finally there is a very high temperature increment (Phase III) as soon as the crack size becomes significant, leading to fracture after a few cycles. This temperature evolution is closely related to the internal microstructural changes, as demonstrated in Fan et al., ${ }^{22}$ and to crack initiation and propagation. ${ }^{23}$ Further studies will be performed in this direction.

\section{DIC analysis}

DIC is a full-field technique for noncontact measurement of displacements and strains. The local displacement versus time and the local hysteresis loop of the specimen were obtained for each test.

The DIC analysis was evaluated after 100 cycles for test no. 8 , the corresponding load range $\Delta F$ is almost $33 \mathrm{kN}$. Figure 11 illustrates a specimen (test no. 8) with superimposed contour plot of the first principal strain range $\Delta \varepsilon_{1}$ of the investigated area. Figure 12 illustrates a $3 \mathrm{D}$ map of the first principal strain range $\Delta \varepsilon_{1}$ (values of $\Delta \varepsilon$ refer to the load range $\Delta F$ ). Some "stage points" were introduced in the DIC images. "Stage points" 0,1 , and 2 were considered at the middle of the lines, located along the surface of the upper continuous plate at a distance, from the 


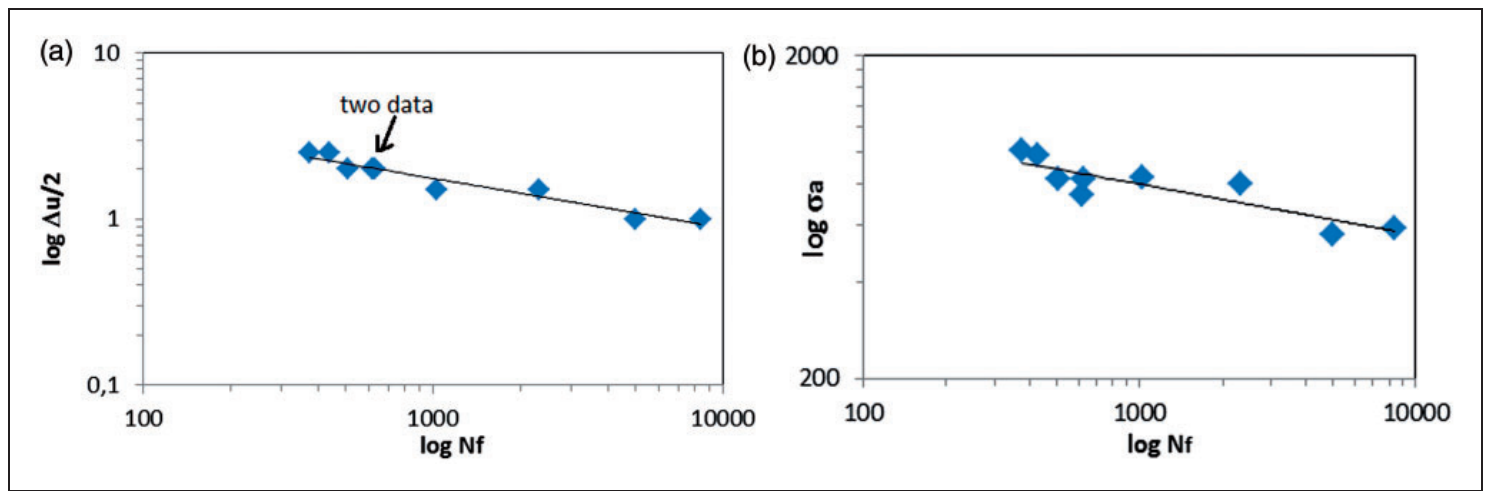

Figure 9. (a) Displacement amplitude $\Delta u / 2$ vs. the fatigue life $N_{f}$; (b) nominal stress amplitude $\sigma_{a}$ vs. the fatigue life $N_{f}$.

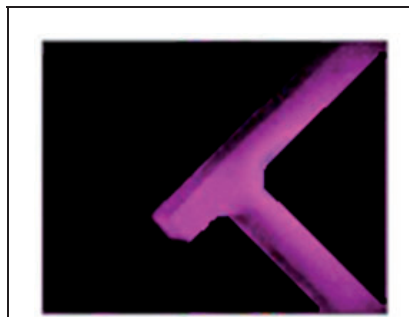

a

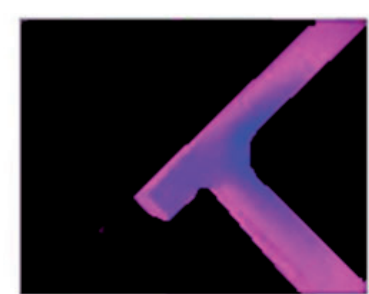

b

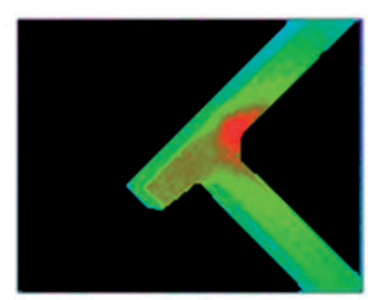

C

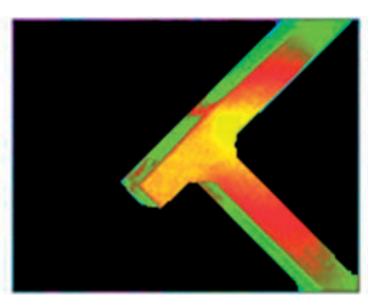

d

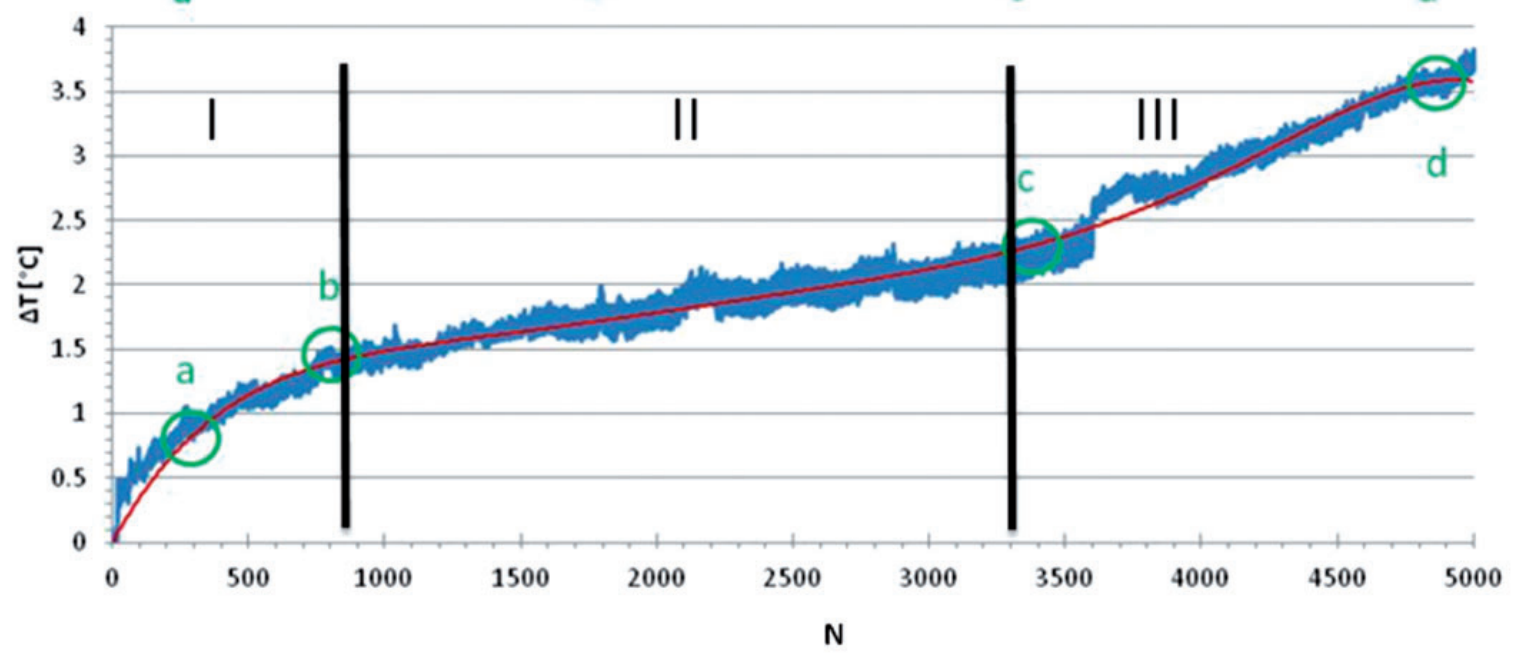

Figure 10. $\Delta T-N$ curve (specimen no. 2).

weld toe, of $32 \mathrm{~mm}, 16.5 \mathrm{~mm}$, and $1 \mathrm{~mm}$; "stage points" 3 and 4 were located on the lower plate at a distance from the weld toe of $1 \mathrm{~mm}$ and $16.5 \mathrm{~mm}$. Figure 12 shows that high strains occur not only in the weld notch, but they extend even along the basematerial surface. Furthermore, the upper part of the specimen is more loaded than the lower one due to the complex structural response of the specimen, some of the main reasons could be directly attributed to the weld geometry, welding-induced residual stresses, and the thicknesses difference between the two plates. Results have shown that strains at maximum and minimum load do not have similar magnitudes, especially for stage points 1,2 , due to the relaxation of residual stresses caused by the welding process. For these reasons, results are shown in terms of strain difference between maximum and minimum load.

Figure 13 illustrates the maximum principal strain versus time for the stage points defined in Figure 12 (the red crosses in Figure 13 indicate the time in which Figure 12 is evaluated); i.e. they yield the strain range because strains at minimum load $(t=0)$ are set to zero.

\section{Cyclic material laws}

The cyclic stress-strain curves of the base material, heat-affected zone, and weld material (BM, HAZ, and $\mathrm{WM}$ ) have to be defined in order to simulate the most representative behavior of the welded specimen. It is well known that the cyclic loading can 


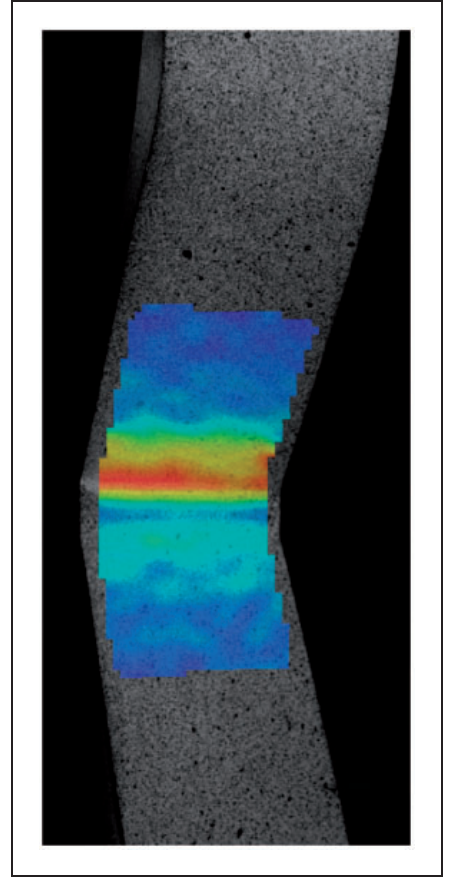

Figure I I. DIC first principal strain range at max. load range.

change the stress-strain behavior of a material and the differences can be evaluated by comparing the material's monotonic and cyclic stress-strain curves. The cyclic stress-strain curve can lie above or below the monotonic stress-strain curve, depending if the material hardens or softens. The cyclic curve is therefore determined through the cyclic strength coefficient $\left(K^{\prime}\right)$ and strain hardening exponent $\left(n^{\prime}\right)$ and can be characterized by the Ramberg-Osgood equation

$$
\frac{\Delta \varepsilon}{2}=\frac{\Delta \varepsilon_{e}}{2}+\frac{\Delta \varepsilon_{p}}{2}=\frac{\Delta \sigma}{2 \cdot E}+\left(\frac{\Delta \sigma}{2 \cdot K^{\prime}}\right)^{1 / n^{\prime}}
$$

In Lopez and Fatemi, ${ }^{19}$ it was observed that the predictive accuracy of cyclic deformation correlations, starting from tensile properties, is improved by grouping steels according to their $\sigma_{u} / \sigma_{y}$ ratios and a separation exists between data of $\sigma_{u} / \sigma_{y}<1.2$ and $\sigma_{u} / \sigma_{y}>1.2$. In particular, the suggested formulas for $K^{\prime}$ and $n^{\prime}$ coefficients calculations, with a confidence of almost $90 \%$, are given in the following equations ${ }^{19}$

$$
\begin{aligned}
& K^{\prime}=1.16 \cdot \sigma_{u}+593, \quad \text { for } \frac{\sigma_{u}}{\sigma_{y}}>1.2 \\
& K^{\prime}=3 \cdot 10^{-4} \sigma_{u}^{2}+0.23 \cdot \sigma_{u}+619, \quad \text { for } \frac{\sigma_{u}}{\sigma_{y}} \leqslant 1.2
\end{aligned}
$$

$$
\begin{aligned}
& n^{\prime}=-0.37 \log \left(\frac{0.75 \cdot \sigma_{y}+82}{1.16 \cdot \sigma_{u}+593}\right) 1.16 \cdot \sigma_{u}+593, \\
& \text { for } \frac{\sigma_{u}}{\sigma_{y}}>1.2
\end{aligned}
$$

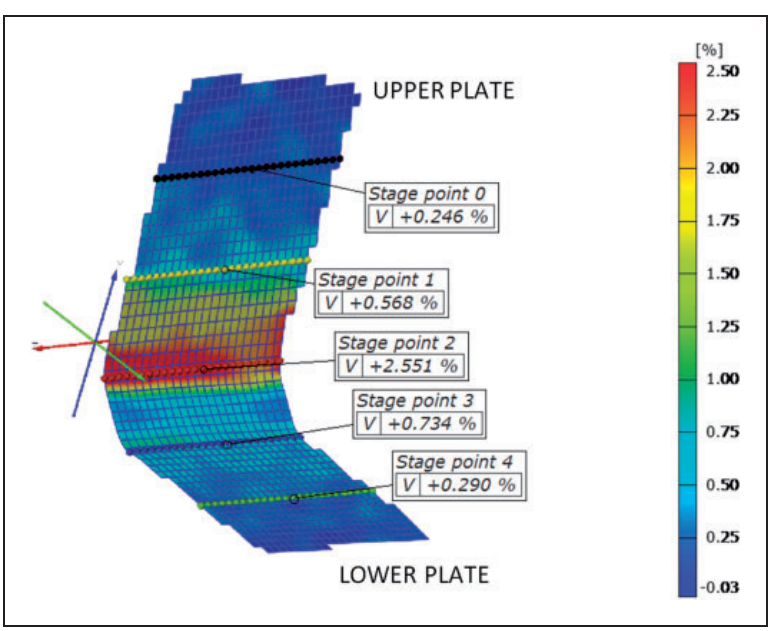

Figure 12. DIC first principal strain range at max. load range.

$$
\begin{aligned}
& n^{\prime}=-0.37 \log \left(\frac{3.10^{-4} \cdot \sigma_{y}{ }^{2}-0.15 \cdot \sigma_{y}+526}{3.10^{-4} \cdot \sigma_{u}{ }^{2}-0.23 \cdot \sigma_{u}+619}\right), \\
& \text { for } \frac{\sigma_{u}}{\sigma_{y}} \leqslant 1.2
\end{aligned}
$$

Since the $\sigma_{u} / \sigma_{y}$ ratio of the welded specimen investigated in this study is greater than 1.2, the cyclic curve coefficients, shown in Table 3, were calculated using equations (4) and (6).

Figure 14 shows a comparison between the cyclic material curves (obtained from the properties given in Table 3) of the three zones, detected from hardness measurements made with the hardness-scanner with high resolution (see Figure 5), and the monotonic stress-strain curve: the base material shows an initial softening and a successive hardening behavior under cyclic loading but the HAZ and the WM show a hardening behavior and almost no initial softening.

\section{Finite element analysis and comparison to DIC results}

ANSYS software was used for the 3D FE nonlinear analysis, with 20-nodes solid elements and multilinear kinematic hardening. The local geometry of the weld is not exactly the same for the investigated specimens, so nominal values (see Figure 4) were assumed for the FE analyses. ${ }^{24}$ Figure 15 shows the local geometry used in the FE model of the notch, with a radius of $1 \mathrm{~mm}$, the minimum size of the elements used in the notch is $0.11 \times 0.09 \times 0.5 \mathrm{~mm}^{3}$, which are respectively on the thickness (radius) direction, circumferential direction, and width direction. The mesh refinement is therefore appropriate according to the IIW recommendation, ${ }^{25}$ which specifies that at least three elements should be used for a notch radius of $1 \mathrm{~mm}$. Figure 15 also shows the different material zones considered in the FE model with their different cyclic stress-strain curves. 
The thickness difference between the two plates was also considered in the FE model.

A comparison between FE and DIC results, in terms of principal strain range, is shown in Figure 16 and the respective values are shown in Table 4. The strain value at stage point 3 has been taken from a region with high strain gradient, which is higher than that obtained by DIC measurement. The grey color indicates very small or negative strain ranges.

Figure 17 shows a comparison during 1.25 cycles for three points of the upper plate, located at a distance $y^{*}$ of $32 \mathrm{~mm}, 16.5 \mathrm{~mm}$, and $1 \mathrm{~mm}$ from the weld toe of the upper plate, in terms of longitudinal strain (indicated in figure as $\varepsilon_{y}$ ). As mentioned before, the measured strains are larger at the maximum load value due to relaxation of residual stresses with respect to the minimum load value, while the FE results show almost the same strain magnitude with different sign. Therefore, Figure 17 shows both, shifted to a mean value close to zero and nonshifted experimental strains, the first being in good agreement with the FE results. A marked difference between nonshifted and shifted values of the experimental strains is observed at a distance from the weld toe equal to $1 \mathrm{~mm}$, it reduces at a distance of $16.5 \mathrm{~mm}$ and finally almost no difference is observed at a distance of $32 \mathrm{~mm}$. However, the strain measured and computed distribution differs near the weld.

\section{DIC and finite element analysis comparison on the cut section}

In order to see the effect of the hardness values on the strain distribution in thickness direction, a comparison of the DIC measurements and FE results on the cut surface of the specimen was made for test no. 9.
As mentioned in section "Hardness measurements", this specimen was cut at half-width for further investigations; the cut section is at the middle of the width of the specimen; therefore two specimens were obtained from a single one in order to have hardness measurements by means of the UCI method and DIC measurements on identical, but opposed cut surfaces. The loading was the same as for test no. 8. The values of von Mises strain range, computed by the FE model and observed by means of the DIC technique, are shown in Figure 18. Figure 19 shows a comparison between strains in the y direction (longitudinal upper plate direction). The grey areas are out of range of the contour plot scale, which is the same for both results. The DIC measurements cannot take into account notch strains measured in this area due to the difficulty to reach points too close to borders or edges, but it is visible that they show a wider area subjected to higher strain than the strain values computed by the FEA. Both comparisons show a general good agreement in identifying the highest strained parts of the specimen. The FE results show also a higher peak strain range in the notch probably due to the different geometry of the real specimen and due to the difficulty for the DIC system to evaluate strains in very sharp notches.

Table 3. Material properties.

\begin{tabular}{llllllll}
\hline & HB & $\begin{array}{l}\sigma_{y} \\
(\mathrm{MPa})\end{array}$ & $\begin{array}{l}\sigma_{u} \\
(\mathrm{MPa})\end{array}$ & $\begin{array}{l}E \\
(\mathrm{MPa})\end{array}$ & $\sigma_{u} / \sigma_{y}$ & $\begin{array}{l}K^{\prime} \\
(\mathrm{MPa})\end{array}$ & $n^{\prime}$ \\
\hline BM & 133 & 332 & 476 & 212,000 & 1.44 & 1144 & 0.20 \\
HAZ & 171 & 390 & 600 & 212,000 & 1.54 & 1289 & 0.20 \\
WM & 219 & 540 & 780 & 212,000 & 1.45 & $145 \mathrm{I}$ & 0.18
\end{tabular}

BM: base material; HAZ: heat-affected zone; WM: weld metal.

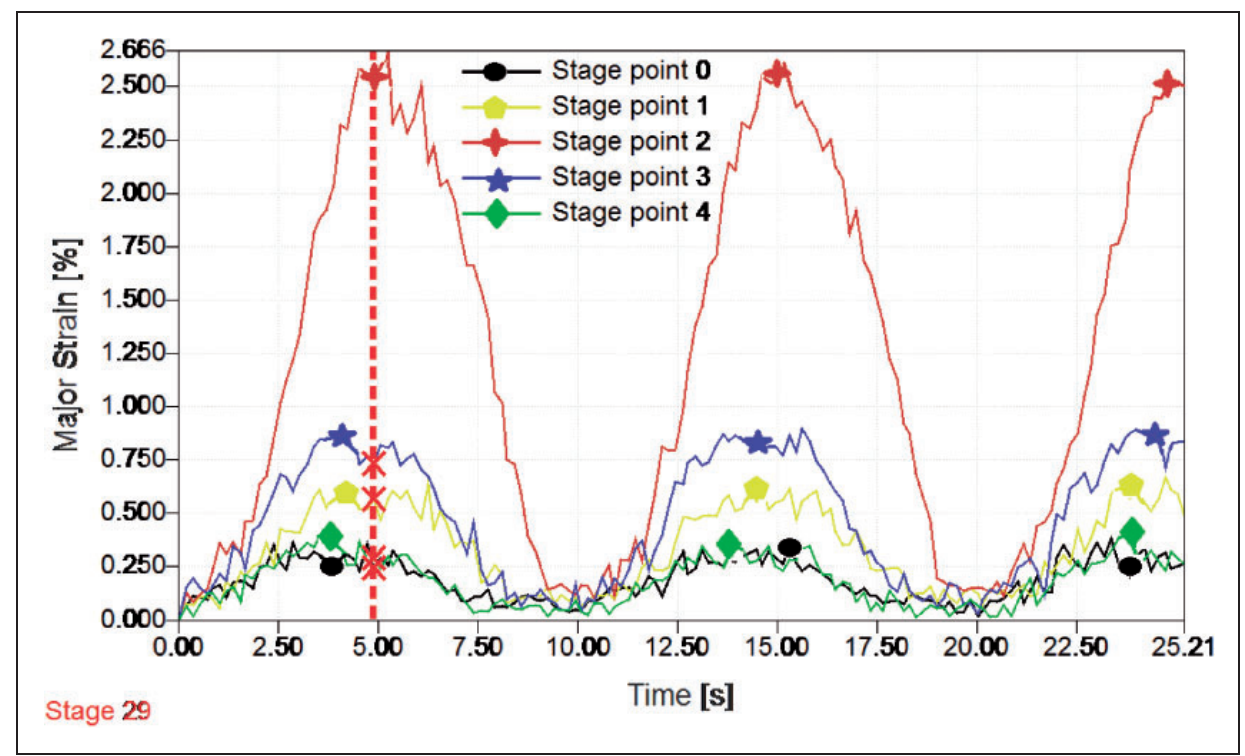

Figure 13. Maximum principal strain range $\Delta \varepsilon_{1}$ vs. time of stage points, for test no. 8 . 


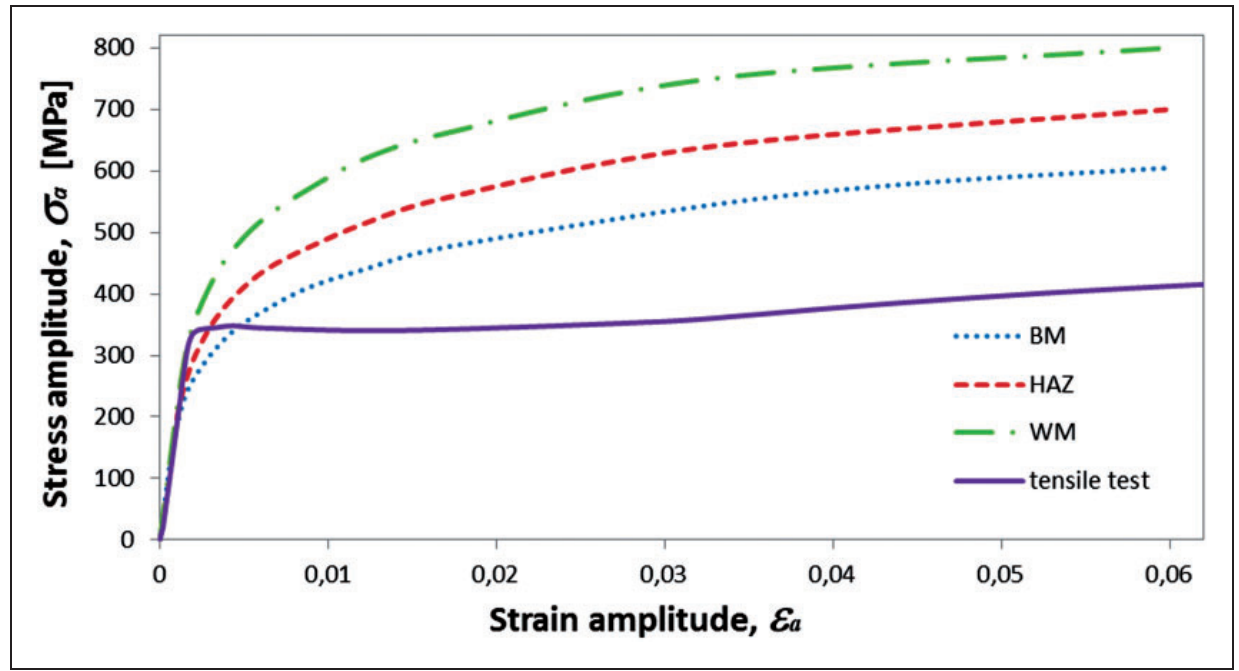

Figure 14. Cyclic curves derived from hardness measurements and tensile stress-strain curve. BM: base material; HAZ: heat-affected zone; WM: weld metal.

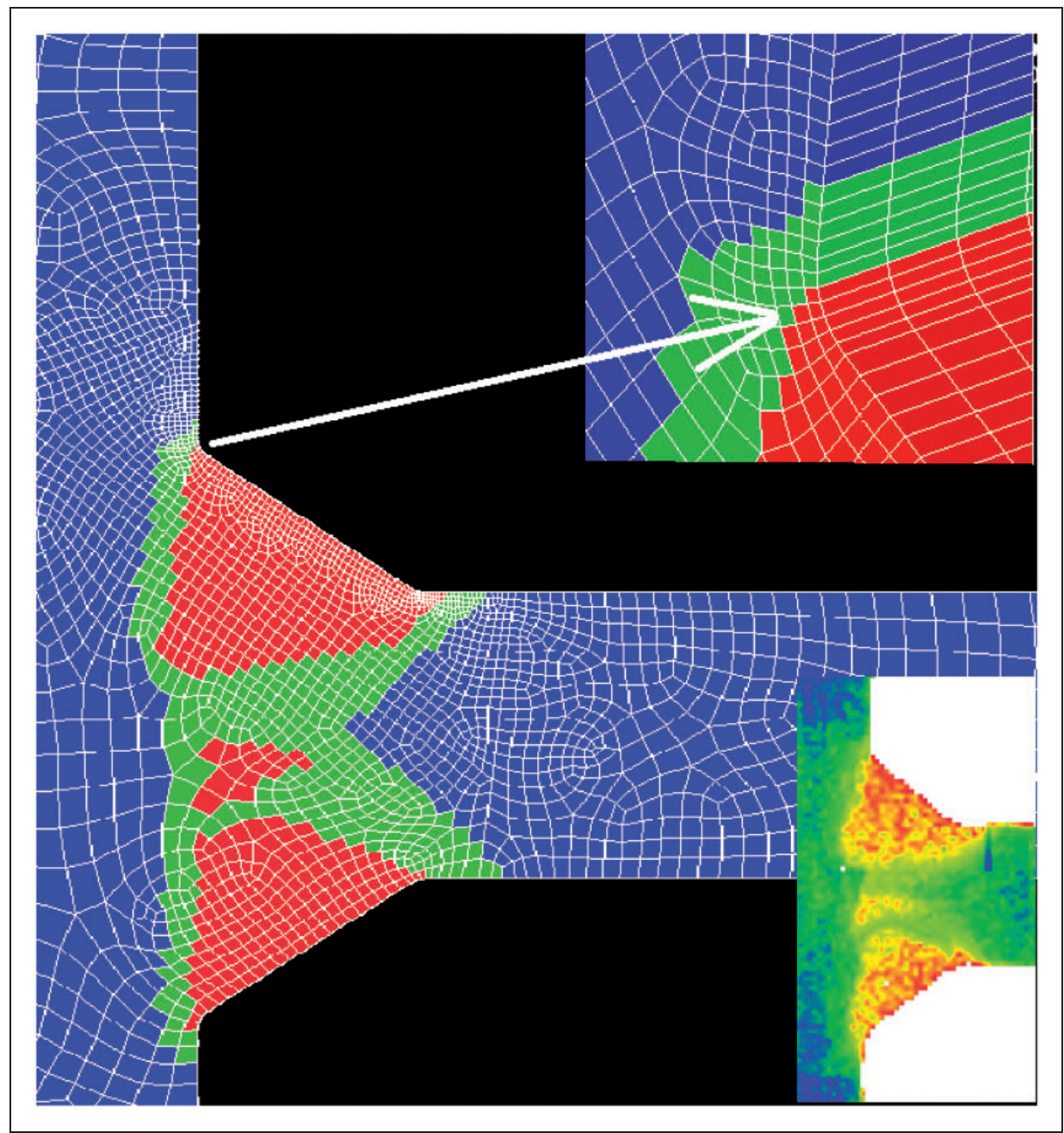

Figure 15. FE model showing mesh fineness and different material zones. 


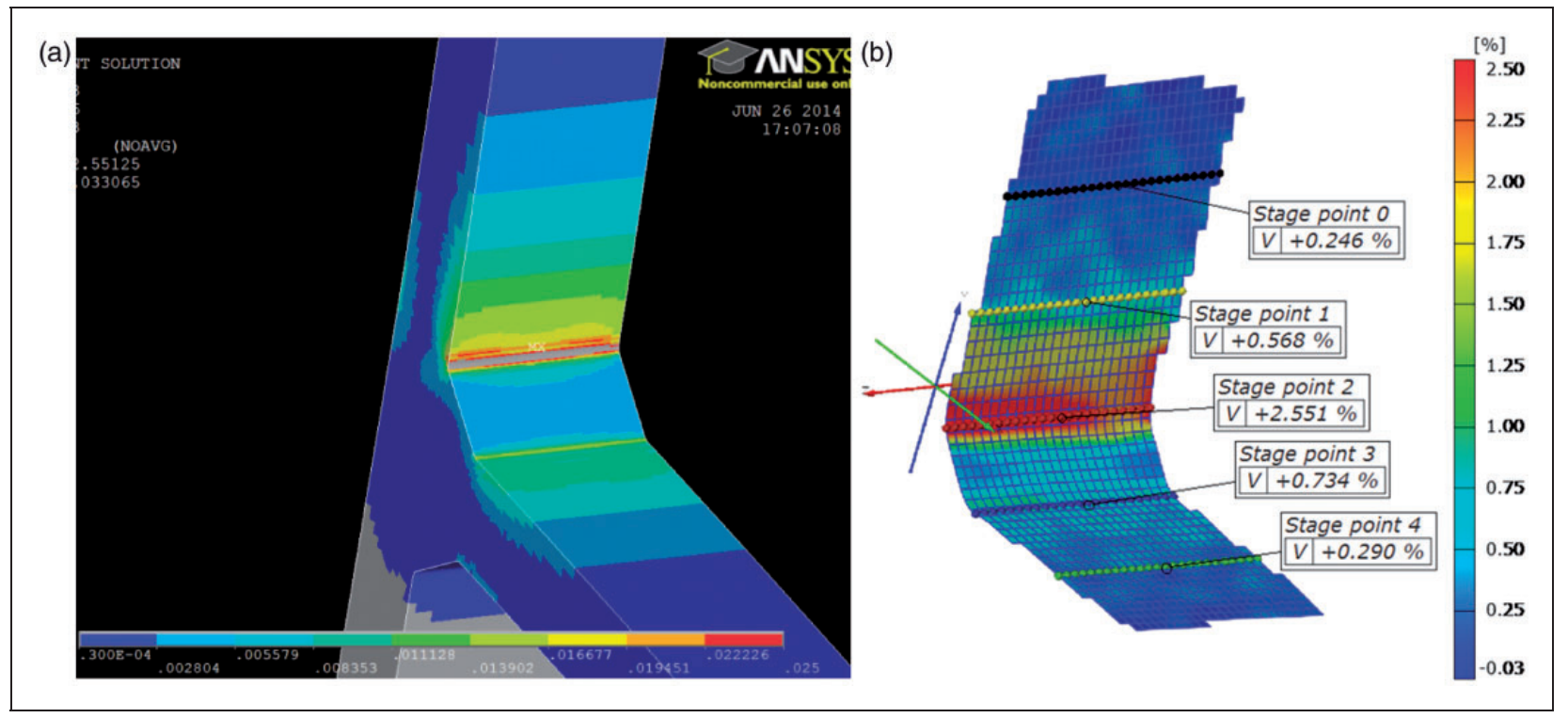

Figure 16. (a) FE first principal strain range at max. load; (b) DIC first principal strain range at max. load.

Table 4. FE-DIC first principle strain range comparison.

\begin{tabular}{lll}
\hline & $\begin{array}{l}\text { FE first principal } \\
\text { strain range (\%) }\end{array}$ & $\begin{array}{l}\text { DIC first principal } \\
\text { strain range (\%) }\end{array}$ \\
\hline Stage point 0 & 0.29 & 0.24 \\
Stage point I & 0.63 & 0.57 \\
Stage point 2 & 2.33 & 2.55 \\
Stage point 3 & 0.82 & 0.73 \\
Stage point 4 & 0.37 & 0.29 \\
\hline
\end{tabular}

FE: finite element; DIC: digital image correlation.

\section{Conclusions}

Two full-field techniques were applied for the study of a fillet-welded joint under LCF loading: DIC and thermographic techniques. The thermographic analysis allowed observing the thermal behavior of the material, characterized by three phases. The DIC measurements of displacement allowed evaluating the strain field, which is not symmetric with respect to the weld, due to the specimen geometry and welding-induced residual stress. A specific procedure was developed to analyze the response of the investigated welded joint under LCF loading. It is based on the following steps: the hardness measurements, using an innovative method for the identification of the different zones (BM, HAZ, and WM) and the assessment of their cyclic stress-strain curves, the realization of a nonlinear FEA considering the different material properties, the validation of the FE model by means of the experimental data, obtained by DIC technique.

The measurements did not cover the strains in the notch of the weld toe which are responsible for the fatigue failure. The problems are the sharpness and the geometric irregularities of the notch root. However, at least in connection with LCF, the

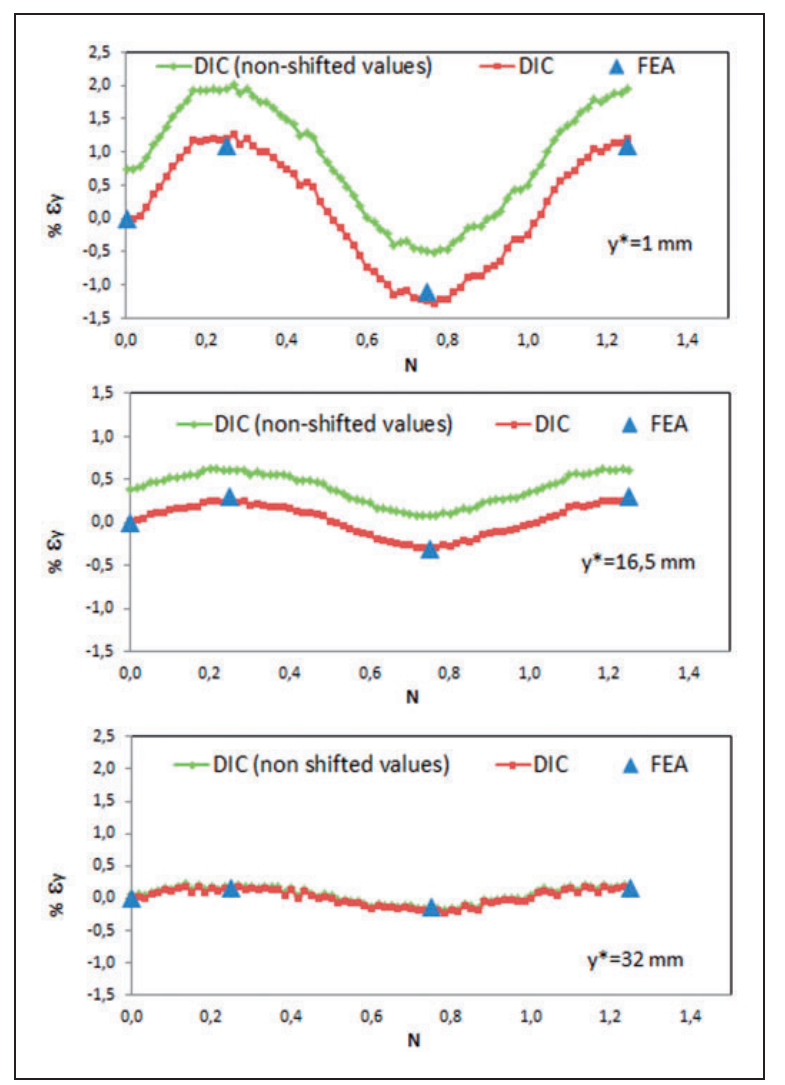

Figure 17. Longitudinal strain in 1.25 cycles, at different distances from weld toe $\left(y^{*}\right)$, of the upper plate.

DIC: digital image correlation; FEA: finite element analysis.

elastic-plastic straining of the base material close to the weld toe determines the loading of the notch and is therefore to be adequately considered. The applied procedure allows providing useful information to the development of models for the prediction of fracture and fatigue behavior of welded joints under LCF loading. 

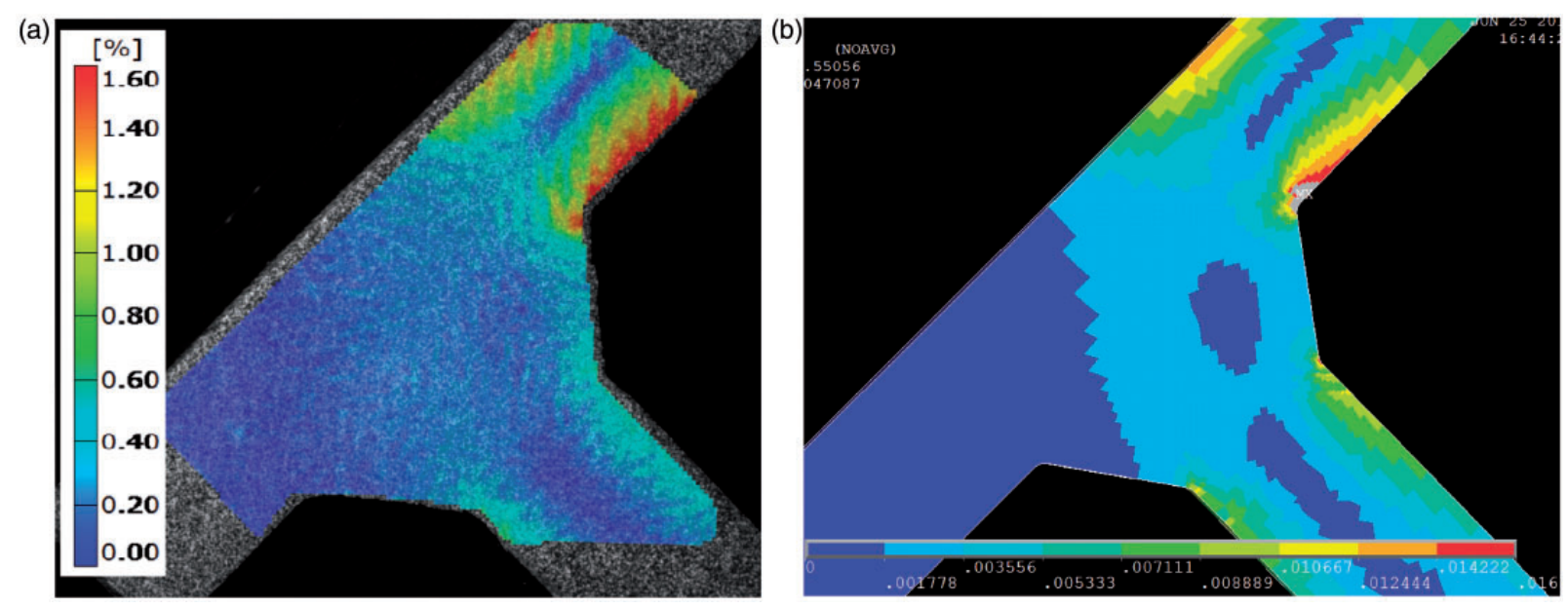

Figure 18. (a) Experimental von Mises strain range; (b) computed von Mises strain range.

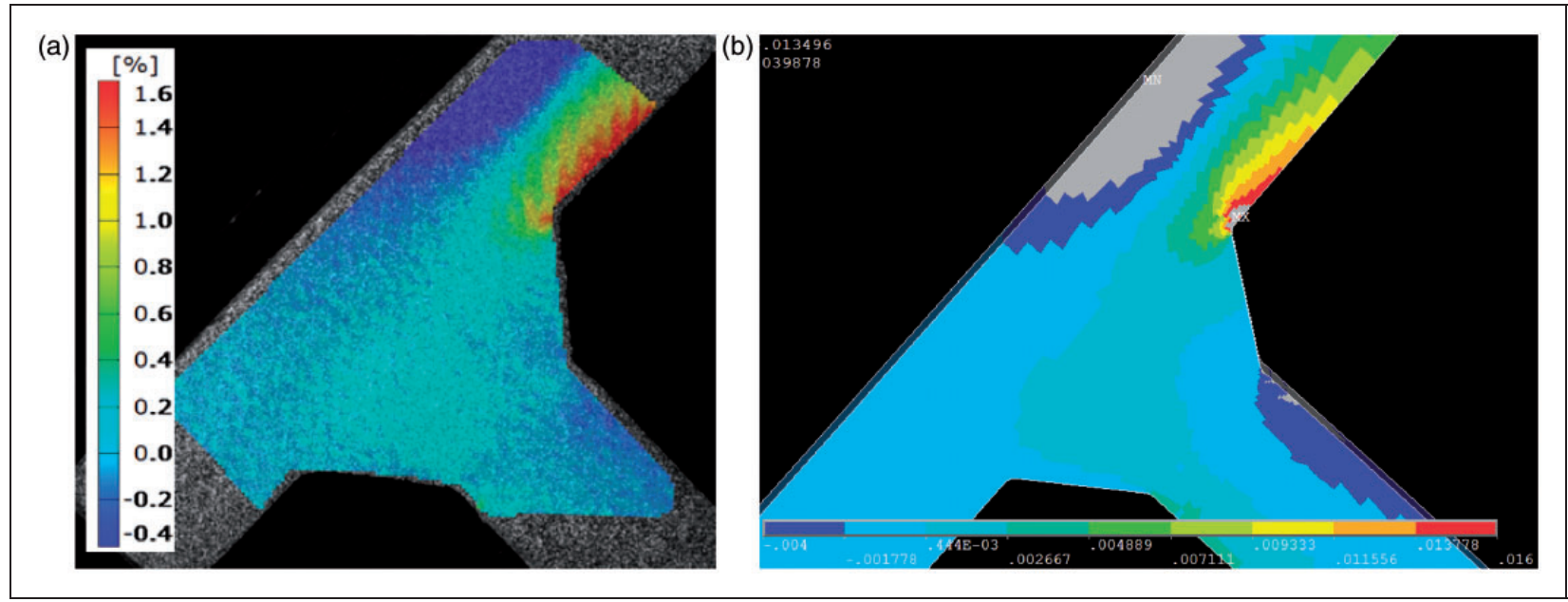

Figure 19. (a) Experimental $y$-strain range; (b) computed $y$-strain range.

\section{Acknowledgements}

The authors are grateful to the Institute of Materials Research, Materials Mechanics, Solid-State Joining Processes at the Helmholtz Zentrum Geesthacht in Germany for the technical support and the efficient cooperation during the hardness measurements.

\section{Conflict of interest}

None declared.

\section{Funding}

This research received no specific grant from any funding agency in the public, commercial, or not-for-profit sectors.

\section{References}

1. ASM Metals handbook, Volume 6, Welding, brazing and soldering. Materials Park, OH: ASM International, 1993.

2. Fricke W. Recent developments and future challenges in fatigue strength assessment of welded joints. Proc
IMechE, Part C: J Mechanical Engineering Science 2014. DOI: $10.1177 / 0954406214550015$.

3. Radaj D, Sonsino CM and Fricke W. Fatigue assessment of welded joints by local approaches. Cambridge: Woodhead Publishing Series, 2006.

4. Radaj D, Sonsino CM and Fricke W. Recent developments in concepts of fatigue assessment of welded joints. Int J Fatigue 2009; 31: 2-11.

5. Dong P. A structural stress definition and numerical implementation for fatigue analyses. Int J Fatigue 2001; 23: 865-876.

6. Sonsino CM, Radaj D, Brandt U, et al. Fatigue assessment of welded joints in AlMg 4.5 Mn aluminium alloy (AA 5083) by local approaches. Int J Fatigue 1999; 21: 985-999.

7. Lazzarin $\mathrm{P}$ and Tovo R. A notch intensity factor approach to the stress intensity of welds. Fatigue Fract Eng Mater Struct 1998; 21: 1089-1103.

8. Atzori B, Lazzarin P, Meneghetti G, et al. Fatigue design of complex welded structures. Int J Fatigue 2009; 31: 59-69. 
9. Taylor D, Barrett N and Lucano G. Some new methods for predicting fatigue in welded joints. Int $J$ Fatigue 2002; 24: 509-518.

10. Crupi V, Guglielmino E, Risitano A, et al. Different methods for fatigue assessment of $\mathrm{T}$ welded joints used in ship structures. J. Ship Res 2007; 51(2): 150-159.

11. Fan JL, Guo XL, Wu CW, et al. Research on fatigue behavior evaluation and fatigue fracture mechanisms of cruciform welded joints. Mater Sci Eng A 2011; 528: 8417-8427.

12. Williams P, Liakat M, Khonsari MM, et al. A thermographic method for remaining fatigue life prediction of welded joints. Mater Des 2013; 51: 916-923.

13. Saiprasertkit K, Hanji T and Miki C. Fatigue strength assessment of load carrying cruciform joints in low and high cycle fatigue region based on effective notch stress approach. Int J Fatigue 2012; 40: 120-128.

14. Chapetti MD and Jaureguizahar LF. Fatigue behavior prediction of welded joints by using an integrated fracture mechanics approach. Int J Fatigue 2012; 43: 43-53.

15. Susmel L. Multiaxial notch fatigue: From nominal to local stress-strain quantities. Cambridge: Woodhead \& CRC, 2009.

16. Sonsino CM. Multiaxial fatigue assessment of welded joints - Recommendations for design codes. Int $J$ Fatigue 2009; 31: 173-187.

17. Susmel L. Nominal stresses and modified Wöhler curve method to perform the fatigue assessment of uniaxially loaded inclined welds. Proc IMechE, Part C: J Mechanical Engineering Science. DOI: 10.1177/ 0954406214522991.
18. Crupi V, Fricke W, Friedrich N, et al. Experimental and numerical analysis of the low-cycle fatigue behaviour of a web frame corner in ships. In: LCF7 Seventh international conference on low cycle fatigue, Aachen, Germany, 17-19 September 2013.

19. Lopez Z and Fatemi A. A method of predicting cyclic stress-strain curve from tensile properties for steels. Mater Sci Eng A: Struct 2012; 556: 540-550.

20. Crupi V, Chiofalo $G$ and Guglielmino E. Infrared investigations for the analysis of low cycle fatigue processes in carbon steels. Proc IMechE, Part C: $J$ Mechanical Engineering Science 2011; 225(4): 833-842.

21. Maletta C, Bruno L, Corigliano P, et al. Crack-tip thermal and mechanical hysteresis in Shape Memory Alloys under fatigue loading. Mater Sci Eng A: Struct 2014; 616: 281-287.

22. Fan J, Guo X, Wu C, et al. Using infrared thermography in effect evaluation of heat treatments on martensitic steel. Exp. Techniques 2014. DOI: 10.1111/ ext.12019.

23. Plekhov OA, Palin-Luc T, Saintier N, et al. Fatigue crack initiation and growth in a $35 \mathrm{CrMo} 4$ steel investigated by infrared thermography. Fatigue Fract Eng Mater Struct 2005; 28: 169-178.

24. Atzori B and Meneghetti G. Fatigue strength of the fillet welded structural steels: Finite elements, strain gauges and reality. Int J Fatigue 2001; 23: 713-721.

25. Fricke W. IIW Recommendations for the fatigue assessment of welded structures by notch stress analysis. Cambridge: Woodhead Publishing, 2012. 